\title{
Uma nova abordagem para o marketing industrial das PMEs: resultados de uma pesquisa-ação
}

Giancarlo Medeiros Pereira UNISINOS

Miriam Borchardt UNISINOS

Albert Geiger IGEA

\section{RESUMO}

Este trabalho apresenta o processo de estruturação da "Feira Reversa", a qual se revelou uma excelente alternativa na criação de espaços de prospecção para as PMEs (empresas de pequeno e médio porte) junto aos fornecedores de primeiro e segundo nível da indústria automotiva, assim como de outros setores empresariais. Ademais, o referido evento igualmente se apresenta como uma ótima opção passível de ser aplicada pelas grandes organizações para a identificação de novos fornecedores de pequeno e médio porte.

\section{PALAVRAS-CHAVE}

Marketing industrial, gestão de mercados, pesquisa-ação.

\section{A new approach to the industrial marketing: an action research study}

\section{ABSTRACT}

This paper presents the process that generated the "Reverse Trade", a new approach to increase the efficiency of the SMEs's (Small and Medium Sized Enterprises) prospecting efforts in the automotive supply chain. On the big companies view, the fair is a good option to increase the agility of their purchasing departments, especially among SMEs.

\section{KEY WORDS}

Industrial marketing, B2B, action-research. 


\section{INTRODUÇÃO}

A indústria automotiva vem deslocando parte de suas atividades produtivas para os fornecedores de primeiro nível com o objetivo de simplificar suas operações industriais e agregar maior valor aos seus parceiros mais diretos (COLLINS; BECHLER; PIRES, 1997; SMOCK, 2001; ZILBOVICIUS et al., 2002).

A tendência descrita também pode ser observada entre os fornecedores do primeiro e segundo nível dessas empresas, os quais igualmente têm direcionado parte de suas atividades produtivas para organizações menores (Mudambi \& Helper, 1998). Entre os motivos que levam a tal postura entre os fornecedores de primeiro e segundo nível, se citem o incremento da diversidade de marcas/modelos e os baixos volumes observados em alguns itens, especialmente em países cuja produção anual de veículos fica aquém dos 3 milhões de unidades/ano.

\section{$\mathbf{V}_{\text {prospecção de oportunidades de longo prazo. }}^{\text {uitas PMEs não possuem recursos para a }}$}

Com efeito, a referida delegação elimina a necessidade de investimentos específicos nas empresas que fornecem diretamente às montadoras, bem como reduz os riscos de obsolescência de uma dada tecnologia, especialmente em itens de baixo/médio volume de produção e/ou complexidade técnica. Esses elementos demonstram a importância das PMEs (pequenas e médias empresas) na viabilização das novas estratégias produtivas das grandes empresas (KRAUSE, 1997; HUMPHREY; LECLER; SALERNO, 2000; TAN; WISNER, 2003). No que tange aos benefícios das PMEs, Tuten \& Urban (2001) e Ambros (2000) destacam que a relação em foco abre novas possibilidades de negócio advindas da melhoria da imagem da PME perante seus clientes bem como colabora para a melhor utilização dos recursos produtivos das mesmas.

Apesar dos benefícios mútuos descritos induzirem ao que Anderson (1995) classificou como geração de valor para o cliente e o fornecedor, muitas PMEs, conforme Santos (2004), não vêm obtendo sucesso em suas tentativas de inserção na referida cadeia produtiva, fato esse que suscita discussões acerca das abordagens que possam viabilizar uma maior integração entre as PMEs e as grandes empresas do primeiro e do segundo nível da cadeia automotiva.

Nesse contexto, o presente trabalho apresenta os resultados de uma pesquisa-ação focada na criação de espaços de prospecção para as PMEs junto aos fornecedores de primeiro e segundo nível da indústria automotiva. O referido trabalho foi apoiado pela Federação das Indústrias e resultou na organização da "Feira Reversa", a qual se caracteriza por ser uma exposição onde os fornecedores da indústria automotiva apresentam itens que devem ter sua produção destinada às PMEs. A característica descrita diferencia a "Feira Reversa" das feiras tradicionais ou dos "encontros de compradores", eis que na mesma é o comprador que expõe suas necessidades imediatas de compra, fato esse que aumenta a eficácia da prospecção das PMEs.

A abordagem descrita viabilizou, até o presente momento, a realização de três eventos, os quais atraíram empresas do porte de GM, GKN Driveline, DANA, DHB, STHIL, TMT MOTOCO, ARVIN MERITOR, DELPHI, LEAR CORPORATION, VALEO, SIEMENS VDO e outras. Além dessas, a "Feira Reversa" atraiu dezenas de pequenas e médias empresas, atuantes ou não, na cadeia automotiva. Em função das peculiaridades da feira, essas PMEs puderam prospectar oportunidades efetivas de novos negócios junto a essas corporações, viabilizando assim o objetivo original do presente projeto.

Na seqüência é apresentada a metodologia adotada, a descrição do processo de geração da feira, a análise das lições auferidas à luz da teoria, as implicações gerenciais advindas do presente estudo, bem como as limitações do mesmo.

\section{METODOLOGIA}

A definição do método de pesquisa da presente investigação levou em consideração os objetivos definidos pela Federação das Indústrias, condição essa que demandava uma abordagem capaz de contemplar o estudo de um problema organizacional conjuntamente com a intervenção prática no mesmo. A análise dos métodos de pesquisa usualmente adotados revelou que apenas o método da pesquisa-ação poderia considerar, de forma simultânea, todos os elementos anteriormente descritos (GUMMESSON, 2000; CHECKLAND; HOLWELL, 1998; GREENWOOD; LEVIN, 1998; EDEN; HUXHAM, 1996; WHYTE, 1991; ARGYRIS et al., 1985; SUSMAN; EVERED, 1978).

Nesse contexto, cumpre aqui destacar as condições em que se recomenda a aplicação do método da pesquisa-ação:

\footnotetext{
"Action Research is appropriate when the research question relates to describing an unfolding series of actions over time in a given group, community or organization; understanding as a member of a group how and why their action can change or im-
} 
prove the working of some aspects of a system; and understanding the process of change or improvement in order to learn from it (COGHLAN; BRANNICK, 2001)."

Uma vez definido o método, foram então analisados os dois elementos básicos que lastreiam a aplicação da pesquisa-ação (PA), a saber: a "relevância para ação", a qual pode ser justificada no plano econômico, político ou social, e a "relevância científica" (SCHEIN, 1999; GUMMESSON, 2000; COUGHLAN \& COGHLAN, 2002).

No que tange à "relevância para ação", a mesma se justifica plenamente em função do interesse de ambos os grupos de empresas de incrementarem suas relações comerciais. A inexistência de muitos estudos focados na efetiva solução dos desafios apresentados confere a "relevância científica" necessária para a realização de um estudo de pesquisa-ação.

Considerando que o referido método pode demandar vários ciclos de ações, conforme demonstrado na Figura 1, inicialmente foram estruturados os passos genéricos necessários à execução de um dado ciclo de ações, a saber: procedimentos para a coleta de dados (qualitativos e quantitativos), formas de repasse dos resultados obtidos aos demais membros do grupo, procedimentos para análise das informações auferidas, abordagem para o planejamento de novas ações, formas de implementação das novas ações definidas e avaliação dos resultados obtidos com as mesmas (SCHEIN, 1999; BECKHARD; HARRIS, 1987; COUGHLAN; COGHLAN, 2002).

Posteriormente, foram definidos os questionamentos passíveis de serem aplicados com vistas à ampliação das informações coletadas. Os passos descritos e a abordagem de questionamento foram aplicados ao longo dos quatro ciclos de ações implementados pelo projeto, os quais serão apresentados na seqüência. A postura adotada pelos investigadores ao longo das etapas foi a de "consultores de processo", conforme proposto por Schein (1999).

Isso posto, o próximo item descreve o processo que levou à criação da "Feira Reversa", sendo que a discussão teórica do mesmo será feita no item seguinte.

\section{O PROCESSO DE CRIAÇÃO DA “FEIRA REVERSA”}

O processo que deu origem à estruturação das "feiras reversas" pode ser dividido em quatro etapas distintas, as quais foram sendo concebidas à medida que os resultados das ações de uma dada etapa anterior eram avaliados. Cada uma dessas etapas almejava, quando de sua concepção, viabilizar os objetivos do projeto definidos pela Federação das Indústrias, a saber: a criação de espaços de prospecção para as PMEs junto aos fornecedores de primeiro e segundo nível da indústria automotiva. Entretanto, conforme será visto ao longo do texto, diversos elementos e interesses influenciaram as opções feitas, fato esse que demandou a execução de várias etapas de trabalho.

Visando descrever em detalhes esses elementos e interesses, este item apresenta as etapas ou ciclos realizados, os quais foram denominados pelos investigadores como: "Etapa dos Compradores", "Etapa Mista”, "Etapa dos Vendedores - Concepção" e "Etapa dos Vendedores - Replicação”. A Figura 2

\section{Coleta de Dados}

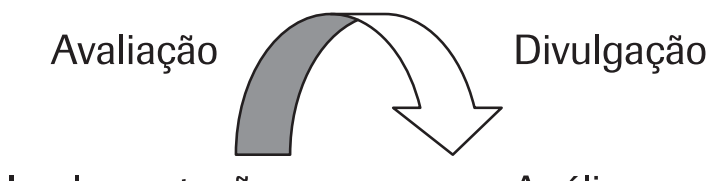

Implementação

Análise

Planejamento

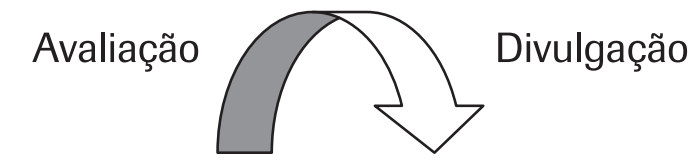

Implementação

Análise

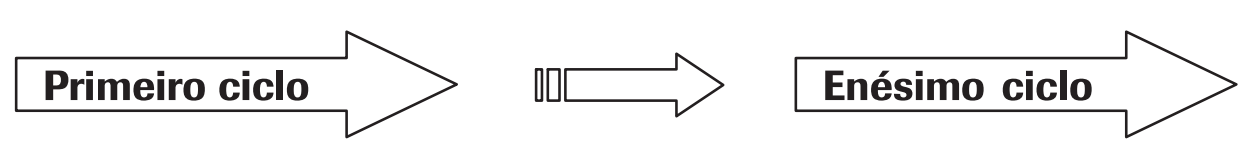

Figura 1: Ciclos de uma pesquisa-ação. 
apresenta um esquema das etapas desenvolvidas. Essa estrutura segue os pressupostos de apresentação dos relatórios de uma pesquisa-ação definidos por Schein (1999); Beckhard; Harris (1987) e Coughlan; Coghlan (2002).

\subsection{Etapa dos Compradores}

A etapa dos compradores teve início com a estruturação do "Comitê de Mercado" pela Diretoria da Federação das Indústrias e se caracterizou pela presença exclusiva de profissionais oriundos dos setores de compras das grandes organizações. A referida concentração advém da indicação dos nomes que foi feita pela Diretoria da Federação. A mesma julgava que a mera indicação de profissionais de grandes organizações que necessitavam ampliar sua base de fornecedores bastaria para viabilizar o objetivo do projeto em foco.

Conforme previsto na metodologia adotada, logo na primeira reunião os membros do comitê foram confrontados com os dados que atestavam a baixa inserção das PMEs na rede de suprimentos das grandes organizações do setor automotivo. A reflexão conjunta acerca dos motivos que induziam a tal contexto revelou uma situação bastante peculiar, a saber: de um lado os compradores das grandes empresas clamavam por novas alternativas de suprimento para itens específicos, itens esses que, segundo os mesmos, deveriam estar sendo supridos por PMEs. De outro, esses mesmos compradores reconheciam a baixa inserção das PMEs locais em suas redes de fornecimento. A análise do cenário descrito levou os membros do comitê a concluírem que o contexto identificado advinha da falta de uma base comum, e justa, para as negociações de preço entre empresas de portes tão distintos.

De posse das conclusões foram então planejadas as primeiras ações do "Comitê de Mercado". Essas ações objetivavam a criação de mecanismos que subsidiassem o processo de negociação entre as partes, processo esse nem sempre amistoso, segundo a maioria dos compradores.
Como exemplo desses mecanismos, cite-se a definição de indicadores para a negociação de preços (de forjados a serviços de alimentação industrial). Além dessas ações, os compradores idealizaram a criação de um portal de compras destinado a reduzir os custos de aquisição das grandes empresas.

Das ações planejadas, apenas o projeto de indicadores de formação de preços foi concluído após um ano de trabalho do Comitê de Mercado, sendo que seu conteúdo foi duramente questionado por um grupo de PMES convidados a opinar sobre o mesmo. Conforme os representantes dessas empresas, o referido projeto era apenas mais uma manobra das grandes para pressioná-las por maiores reduções de preço.

A avaliação dos resultados obtidos ao longo do primeiro ano foi realizada com base em questionamentos simples e de confrontação, feitos aos representantes das empresas envolvidas, conforme definido por Schein (1999). A referida avaliação revelou que as ações desenvolvidas pelos representantes das grandes organizações pouco haviam colaborado para a viabilização dos objetivos definidos para o comitê.

Objetivando reverter o quadro identificado, os membros do comitê propuseram que fosse alterada a composição do mesmo mediante a inclusão de um maior número de PMEs. Segundo os proponentes, tal ação haveria de neutralizar o forte viés "comprador" existente no "Comitê de Mercado".

Uma vez aprovada a proposta, cada grande empresa ficou encarregada de escolher, dentro de sua base de fornecedores, algumas PMEs capazes de atender aos padrões automotivos. Dessa forma deu-se início à segunda etapa, a saber, a "Etapa Mista". O próximo tópico analisa os desdobramentos da mesma.

\subsection{Etapa Mista}

Nesta nova etapa foram introduzidos no "Comitê de Mercado" empreendedores e gestores de vendas oriundos
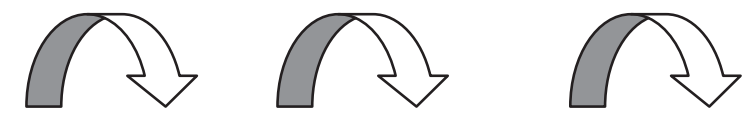

$\begin{array}{llll}\text { Etapa dos } & \text { Etapa } & \text { Etapa dos } & \text { Etapa dos } \\ \text { Compradores } & \text { Mista } & \text { Vendedores } & \text { Vendedores } \\ & & \text { Concepção } & \text { Replicação }\end{array}$

Figura 2: Etapas do processo de criação da "Feira Reversa". 
de PMEs que já participavam da rede de fornecedores das grandes empresas automotivas localizadas no estado. Esses profissionais, juntamente com os compradores da etapa anterior, formaram o grupo de trabalho desta etapa.

Logo nas primeiras reuniões foi possível observar-se a grande diferença de posturas e objetivos de ambas as partes ante os objetivos definidos para o referido comitê. De um lado estavam grandes empresas, as quais permaneciam carentes de fontes alternativas de suprimentos em nível de PMEs. De outro lado estavam os representantes de algumas PMEs já atuantes na cadeia, as quais buscavam no comitê uma forma de se aproximar ainda mais de outras grandes compradoras, aumentando assim as suas possibilidades de geração de novos negócios no setor.

Nesse contexto, os representantes das grandes empresas, apoiados em seu enorme poder de compra, acabaram novamente por direcionar as discussões para a definição de indicadores que pudessem justificar uma maior redução nos preços dos itens comprados das PMEs. Interessadas em manter suas boas relações com seus tradicionais clientes, os representantes das PMEs já atuantes na cadeia acabaram por aceitar tal enfoque.

Após um novo ano de atividades, a avaliação das ações executadas pelo comitê foi classificada como "insuficiente" para a viabilização dos objetivos definidos para o grupo de trabalho pela Federação das Indústrias. Confrontados com as informações de que poucos novos negócios haviam sido viabilizados entre grandes e PMEs ao longo da etapa em análise, os membros do "Comitê de Mercado" propuseram a divisão do mesmo em dois comitês distintos, a saber: um destinado às PMEs, e outro destinado às grandes empresas. Do primeiro participariam os empresários e gestores de venda das PMEs, e do outro os executivos de compra das grandes empresas.

Embora a proposta de divisão do comitê parecesse interessante do ponto de vista lógico, algumas PMEs temiam que sua implementação pudesse fazer com que as grandes empresas retirassem seu apoio às novas ações desenvolvidas pelo novo comitê de vendedores. Com efeito, esse temor quase inviabilizou a mudança em análise. Contudo, a falta de avanços significativos após um ano de trabalho acabou por determinar que o "Comitê de Mercado" passasse a se focalizar nas questões de interesse dos departamentos de suprimentos das grandes corporações, enquanto que o novo comitê formado, o "Comitê de Promoção e Marketing Industrial", se focalizaria nas questões de interesse das PMEs. Essa divisão deu início a uma nova etapa, a qual será descrita na seqüência.

\subsection{Etapa dos Vendedores - Concepção da Feira}

A criação de um comitê exclusivo para os vendedores das PMEs, ao contrário do que originalmente se supunha, não se refletiu em um esvaziamento do novo fórum. Muito pelo contrário. Ao novo comitê acorreram diversas PMEs, muitas delas atuantes em outras cadeias produtivas que não a automotiva. Em comum entre os novos membros estava o desejo de venderem parte de sua capacidade produtiva ociosa para a referida cadeia. Contudo, permanecia pendente a questão: Como viabilizar espaços de prospecção para as PMEs junto aos fornecedores de primeiro e segundo nivel da cadeia automotiva?

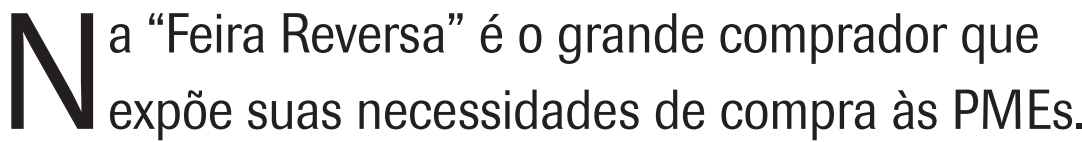

Objetivando responder ao questionamento acima, o "Comitê de Promoção e Marketing Industrial" propôs a organização de uma feira de PMEs, nos moldes das feiras tradicionais, idéia essa que logo foi abandonada em função do grande número de feiras tradicionais existentes na região.

Contemplando a demanda das grandes empresas por produtos altamente específicos e o desconhecimento das PMEs sobre as reais demandas de muitas das grandes empresas, um empresário de uma média organização propôs a criação de uma "feira de interesses". Segundo o mesmo, essa feira não apresentaria as capacidades e competências das PMEs como usualmente é feito nas feiras tradicionais, mas sim as necessidades reais de compra das grandes empresas. Segundo seu mentor, a referida "feira de interesses" se caracterizaria por apresentar, em um único local, as demandas das grandes empresas. Inicialmente batizada de "Feira de Compradores", a mesma posteriormente foi denominada de "Feira Reversa", eis que a referida invertia totalmente a lógica de uma feira.

Inicialmente a idéia da "Feira Reversa" encontrou uma relativa oposição dentro do próprio "Comitê de Promoção e Marketing Industrial", fato esse que demandou uma consulta ao "Comitê de Mercado" acerca dos interesses do referido comitê pelo evento em foco. Para surpresa geral, o resultado da consulta revelou que a idéia era muito bem recebida pelos executivos da área de suprimentos das grandes empresas, tanto que suas empresas estavam dispostas a expor os itens cuja produção poderia ser delegada às PMEs. Além disso, as mesmas também se dispuseram a arcar com todos os custos da "Feira Reversa" (mídia, aluguel do local etc.).

Com base no apoio das grandes empresas da cadeia automotiva, o grupo de trabalho passou a organizar o evento. Durante essa fase, representantes de PMEs do comitê iden- 
tificaram, junto à sua base de clientes atuantes fora da cadeia automotiva, duas grandes empresas interessadas em expor suas necessidades de compra na "Feira Reversa". Essa adesão voluntária demonstrou que a idéia da feira poderia interessar a outras empresas produtoras de máquinas e equipamentos, e não somente ao setor automotivo como inicialmente se supunha. O Quadro 1 apresenta o perfil das empresas que expuseram na $1^{\underline{a}}$ Feira Reversa.

O perfil dos expositores e a grande diversidade de itens apresentada atraíram 63 pequenas e médias empresas para a primeira edição da "Feira Reversa". Conforme dados da pesquisa de satisfação realizada pela Federação das Indústrias, o evento atendeu às expectativas tanto das grandes quanto das PMEs. De parte das grandes, a referida satisfação adveio do fato de que as mesmas puderam, em um único dia, e a um custo ínfimo, identificar um mínimo de 15 potenciais fornecedores de usinados, fundidos, borrachas, plásticos etc. Conforme declarado por um executivo do setor de suprimentos de uma das grandes empresas participantes, a efetivação desses contatos custaria à grande empresa pelo menos 45 dias de trabalho de um analista de compras, eis que muitas das PMEs identificadas nunca haviam tido contato com os expositores. No que tange às PMEs, a satisfação se deve ao fato de que em poucas horas as mesmas tiveram acesso a um conjunto de possibilidades de negócio cuja concretização dependeria apenas da adequação da empresa aos requisitos de qualidade e preço do pretenso cliente.

A avaliação positiva do evento induziu à organização de novos eventos, dando início assim à fase de replicação, a qual será descrita na seqüência.

\subsection{Etapa dos Vendedores - Replicação da Feira}

A rápida identificação de potenciais fornecedores verificada na primeira feira motivou as expositoras a realizarem um novo evento para expor outros itens passíveis de delegação às PMEs, itens esses que não haviam sido expostos na primeira edição. Além dos expositores do primeiro evento, a segunda feira contou com a participação da Johnson Controls (multinacional produtora de computadores de bordo, painéis de instrumentos, sensores de velocidade, etc.) e de quatro empresas nacionais, a saber: Irmãos Galleazzi (metais não-ferrosos), Artstampo (produtora de terminais elétricos, peças automotivas, peças para a indústria moveleira, insertos metálicos etc.) e duas empresas de serviço, uma na área de transportes, e outra do setor financeiro.

Os dados coletados pela Federação das Indústrias indi-

Quadro 1: Empresas participantes da terceira edição.

\begin{tabular}{cr}
\hline Empresa & Perfil \\
\hline GKN Driveline & $\begin{array}{r}\text { Multinacional produtora de juntas homocinéticas e peças de metal em pó para a indústria automotiva. } \\
\text { DANA }\end{array}$ \\
Multinacional produtora de eixos e diferenciais, cardans, transmissões, chassi, \\
direção e suspensão, tubulações, anéis, bombas etc. para a indústria automotiva. \\
STHIL & $\begin{array}{c}\text { Multinacional produtora de motosserras, roçadeiras, } \\
\text { TMT notoco nacional produtora de bombas, mangueiras e mecanismos de direção veicular. }\end{array}$ \\
& $\begin{array}{r}\text { Multinacional produtora de motores de combustão interna, transmissões, compressores } \\
\text { herméticos, unidades condensadoras para refrigeração, bombas e motores elétricos. }\end{array}$ \\
\hline
\end{tabular}

Quadro 2: Empresas participantes da terceira edição.

\begin{tabular}{cc}
\hline Empresa & Perfil \\
\hline ARVIN MERITOR & Componentes automotivos e escapamentos \\
DELPHI & CD players, baterias, injeção eletrônica, sistema de navegação etc. \\
LEAR CORPORATION & Assentos \\
VALEO & Sistemas de limpadores, ar condicionado, iluminação, segurança etc. \\
SIEMENS VDO & Equipamentos eletrônicos e mecatrônicos. \\
\hline
\end{tabular}


cam que 81 PMEs acorreram ao evento, sendo que a satisfação de ambos os grupos de empresas ficou no mesmo nível da feira anterior.

A divulgação dos resultados positivos entre os membros da Federação das Indústrias motivou a GM (General Motors) e seus fornecedores de primeiro nível a organizarem uma feira exclusiva. Conforme um executivo da montadora, a possibilidade de identificação de fontes alternativas de suprimentos para os itens "não estratégicos" era tida como prioritária para a sua empresa, bem como para seus parceiros mais diretos. O Quadro 2 apresenta o perfil das multinacionais atuantes no primeiro nível da cadeia de suprimentos da GM que expuseram na terceira edição da feira.

O perfil das empresas expositoras associada à diversidade e à quantidade de itens expostos atraíram para a Federação das Indústrias 146 empresas de pequeno e médio porte atuantes em atividades e setores (da produção de peças plásticas para a indústria de máquinas agrícolas ao fornecimento de adereços metálicos para a indústria moveleira). Com efeito, a elevada participação igualmente pode ser creditada à percepção, por parte das pequenas e médias, de que a "Feira Reversa" efetivamente se constituía em uma boa oportunidade para a prospecção de novos negócios junto às grandes empresas.

O Gráfico 1 analisa a evolução da participação das PMEs nas "Feiras Reversas" ao longo das três edições realizadas.
Uma vez apresentado o processo que deu origem às "Feiras Reversas", o próximo tópico apresentará uma reflexão à luz da teoria sobre o processo em foco.

\section{DISCUSSÃO TEÓRICA}

A reflexão dos pesquisadores acerca dos aprendizados auferidos durante a interação desenvolvida constitui-se em uma etapa essencial do método da pesquisa-ação (MCNIFF et al., 1996; COGHLAN; BRANNICK, 2001). Entretanto, é essencial que essa reflexão seja feita à luz da teoria, colaborando assim não somente para a solução de um problema real, mas, principalmente, contribuindo para a geração de conhecimento científico (COUGHLAN; COGHLAN, 2002).

Nesse contexto, os próximos parágrafos apresentam as reflexões dos pesquisadores acerca de tais aprendizados.

\subsection{Análise da Etapa dos Compradores}

A análise dos desdobramentos da "Etapa dos Compradores" fornece indícios de que a criação de relacionamentos entre grandes e PMEs em uma cadeia produtiva complexa como a automotiva não pode ser baseada unicamente no apoio das grandes empresas que eventualmente estejam interessadas em encontrar novas opções de fornecimento entre as PMEs.

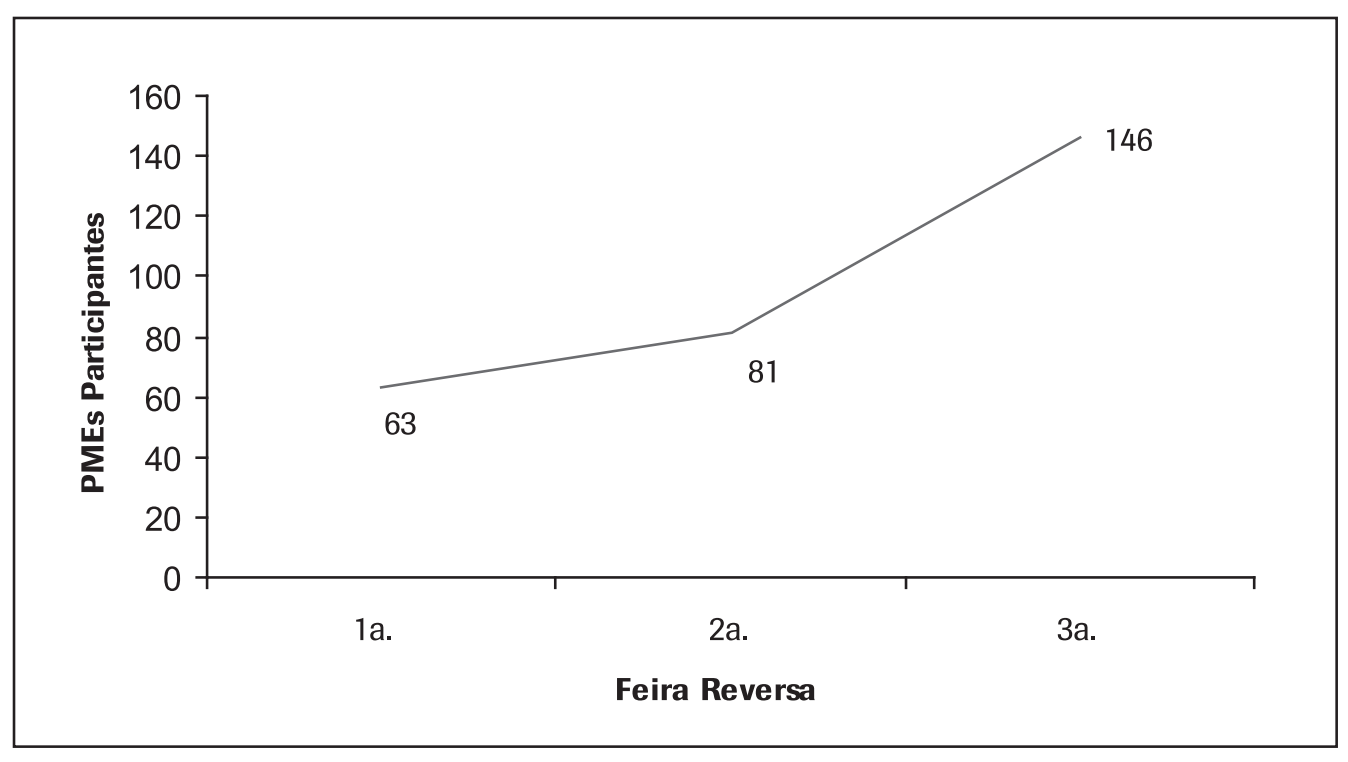

Gráfico 1: Evolução da participação das PMEs. 
Essa constatação é referendada por Cousins e Crone (2003), Krause et al. (2000), Krause e Scanell (2002), os quais postulam que os movimentos realizados pelas grandes organizações objetivam apenas reduzir seus custos de compra mediante o aumento da competição entre seus fornecedores aptos a produzirem um dado item. Esse contexto é especialmente observado na aquisição de itens classificados como "não estratégicos", ou seja, itens de baixo/ médio custo ou complexidade técnica, os quais tipicamente são manufaturados por PMEs. A conjunção dos elementos descritos ao longo da cadeia automotiva provoca uma permanente alteração do mix de fornecedores, conduzindo ao que Kamp (2005) denominou de "instabilidade no relacionamento B2B".

\section{A pesquisa-ação um problema organizacional é estudado conjuntamente com a intervenção}

\section{prática no mesmo.}

\subsection{Análise da Etapa Mista}

A análise das lições auferidas nessa etapa permite concluir que as PMEs já atuantes na rede automotiva não se interessam em viabilizar novos relacionamentos entre PMEs de fora da cadeia e as grandes organizações do setor. Em verdade, as PMEs já atuantes na cadeia que se inseriram no comitê objetivavam apenas estreitar seus laços com as grandes empresas, relegando a um segundo plano os objetivos originais do projeto. O contexto descrito colaborou significativamente para que as ações do comitê fossem ditadas pelos interesses das grandes empresas, conforme já havia sido observado na etapa dos compradores. Em decorrência disso, as discussões do grupo de trabalho permaneceram centradas na busca de opções para a redução de custos dos itens adquiridos junto às PMEs. A análise da relação em foco pode ser classificada como "relação de dominação por parte do comprador", conforme proposto por Cox (2004).

Desta forma, pode-se postular que o insucesso da "Etapa Mista" se relaciona à diferença de objetivos existente entre as organizações envolvidas, conclusão esta que se alinha com a obtida nos trabalhos de Spekman (2006) e Giannoccaro e Pontrandolfo (2003). Segundo os referidos autores, a diferença de objetivos organizacionais é um fator que induz à redução de performance de uma dada cadeia produtiva.

Ao refletir sobre as conclusões das etapas dos "compradores" e "mista", poder-se-ia argumentar que as mesmas eram previsíveis do ponto de vista lógico, fato esse que dispensaria a execução das referidas etapas, economizandose assim dois anos de trabalhos infrutíferos no referido comitê. Todavia, a realidade da interação entre empresas de tamanhos diferentes, sob o patrocínio de uma associação empresarial, revela que nem sempre o caminho mais curto entre dois pontos é definido por uma reta. Com efeito, a viabilização dos objetivos da presente pesquisa-ação demandou uma construção conjunta de caminhos entre os diferentes agentes envolvidos. Nesse contexto, a melhor opção somente é encontrada após o teste de algumas alternativas que, apesar de equivocadas, eram originalmente tidas como válidas pelos executivos e empresários que participaram de sua concepção. Em verdade, o avanço neste tipo de investigação somente se faz quando as "boas idéias" passam pelo duro teste da realidade.

\subsection{Análise da Etapa dos Vendedores - Concepção}

A análise dos desdobramentos da "Etapa dos Vendedores" permite concluir que a aproximação de PMEs com as fornecedoras de primeiro e segundo nível da cadeia automotiva é mais facilmente viabilizada no momento em que empresas de mesmo porte se unem para, juntas, desenvolverem ações cooperativas que se encaixem em suas perspectivas e objetivos empresariais.

Nesse contexto, a separação entre vendedores e compradores permitiu que cada grupo orquestrasse, em seu respectivo comitê, ações direcionadas à viabilização dos interesses de seus membros. Analisando-se o apoio recebido pela proposta da "Feira Reversa" junto aos dois grupos em foco, pode-se argumentar que o mesmo adveio do fato de que o referido evento atendia aos objetivos de ambos os grupos, a saber: a possibilidade de identificação, a baixo custo, de novas fontes de suprimentos para as grandes empresas e a criação de um novo e mais eficaz canal de prospecção para as PMEs.

Além disso, a divisão em grupos permitiu uma maior cooperação entre os vendedores das PMEs. Como exemplo dos benefícios dessa cooperação, cite-se o fato de que a junção de profissionais de vendas oriundos de PMEs no "Comitê de Promoção e Marketing" suscitou um ciclo virtuoso de troca de informações entre as empresas acerca das oportunidades de negócios existentes tanto na cadeia automotiva, como fora desta. A cooperação entre pares descrita reforça a percepção de Sydow (1996), Ring e Van De Ven (1994), Easton (1992), Jarillo (1988) e Tichy (1981), os quais postulam que as PMEs, em função de seus limitados recursos e competências, precisam cooperar para se desenvolverem em mercados altamente turbulentos. Nesse sentido, os conhecimentos auferidos na presente etapa igualmente se alinham aos trabalhos de Loeser (1999), Link 
e Marxt (2004), Johnston et al. (2004), Amato Neto (2000), Casarotto Filho e Pires (1999) e Doz e Hamel (1998).

\subsection{Análise da Etapa dos Vendedores - Implantação}

A análise das trocas de informações acerca de oportunidades de negócio realizadas entre os vendedores das PMEs revela que as mesmas somente se deram entre empresas "não concorrentes" (ex. PMEs fabricantes de borracha colaboraram com PMEs fabricantes de forjados). Em verdade, os pesquisadores não identificaram trocas de informações relevantes entre empresas de um mesmo ramo de atividade. Essa informação confirma a percepção de Bengtsson e Kock (2000) de que as empresas concorrentes tendem a cooperar mais facilmente entre si somente quando o comprador está distante de suas unidades, condição essa que não se verificou no caso em análise.

Quanto à cooperação entre os diferentes grupos de organizações, há que se destacar que a mesma foi muito influenciada pelas intervenções mediadoras da Federação das Indústrias, entidade neutra reconhecida por ambas as partes, cuja presença se constitui em um elemento essencial para a viabilização da cooperação empresarial (RICH; HINES, 1997).

Em se tratando da satisfação, os dados divulgados pela Federação das Indústrias indicam que a "Feira Reversa" se constitui em uma ótima opção para a intervenção em cadeias produtivas com vistas à geração de novos negócios entre grandes e PMEs. A referida constatação é referendada por ambos os grupos de empresas. No que tange às grandes organizações, a satisfação advém do fato de que a "Feira Reversa" permitiu a rápida e barata identificação de novos fornecedores. Quanto às PMEs, especialmente aquelas que buscam atuar em diferentes cadeias produtivas, a satisfação para com a "Feira Reversa" advém do fato de que a mesma conferiu uma maior eficácia aos seus esforços de prospecção de novos negócios junto às grandes organizações.

Por fim, cumpre destacar que, apesar da relevância do tema, a literatura de marketing industrial consultada não apresentou nenhum trabalho cujo foco fosse a estruturação de eventos similares à "Feira Reversa" como forma de aumentar a eficácia da prospecção das PMEs em cadeias produtivas complexas como a automotiva.

\section{IMPLICAÇÕES GERENCIAIS}

O presente estudo apresentou uma nova abordagem passível de ser utilizada pelos gestores de marketing indus- trial das PMEs para a prospecção, a baixo custo, de novos negócios junto aos fornecedores de primeiro e segundo nível da cadeia automotiva, ou mesmo junto a grandes empresas atuantes em outros setores industriais. Esses conhecimentos igualmente são de interesse dos gestores de compra das grandes organizações, os quais podem, através da abordagem apresentada, identificar novas fontes de suprimento junto às PMEs.

\section{A "Feira Reversa" permitiu a rápida e barata identificação de novos fornecedores.}

Objetivando orientar os interessados na replicação da experiência em foco, este artigo descreve os elementos que colaboraram para a viabilização da referida feira, bem como as dificuldades encontradas pelo grupo ao longo do processo.

Igualmente são apresentados uma série de argumentos que podem ser utilizados tanto pelos gestores de marketing das PMEs, como pelos gestores de compra das grandes organizações, quando da proposição de uma nova "feira reversa".

\section{LIMITAÇÕES DESTE ESTUDO}

Como todo relatório de pesquisa-ação, o presente trabalho concentrou-se na apresentação dos desdobramentos que viabilizaram o objetivo da mesma, qual seja: a criação de espaços de prospecção para as PMEs junto aos fornecedores de primeiro e segundo nível da indústria automotiva. Adicionalmente, foram criadas condições para que as PMEs igualmente prospectassem negócios fora da cadeia automotiva, fato esse que extrapolou positivamente os objetivos originais do projeto em foco.

Contudo, esse artigo não apresenta o volume de negócios gerado entre grandes e PMEs em decorrência das três "Feiras Reversas" realizadas. Com efeito, este não era o objetivo do presente. Nesse contexto, a quantificação do retorno auferido por grandes empresas e por PMEs será feita em uma investigação futura.

A replicação desse estudo em outros cenários requer a observação das condições descritas neste artigo. Ademais, a referida implementação demandará uma considerável habilidade por parte dos responsáveis pela condução do processo, haja vista a dificuldade de se orquestrar a colaboração empresarial entre organizações com objetivos e portes tão distintos. 


\section{CONCLUSÕES}

O presente estudo apresentou os desdobramentos de uma pesquisa-ação realizada com o objetivo de criar espaços de prospecção para as PMEs junto aos fornecedores de primeiro e segundo nível da indústria automotiva.

Os resultados desse estudo levaram à estruturação da "Feira Reversa", a qual satisfez tanto às grandes empresas, quanto às PMEs. De parte das grandes, a descrita satisfação advém do fato de que a feira permitiu a tais organizações rapidamente identificar novos fornecedores capazes de assumir a produção de itens altamente específicos, per- mitindo, assim, uma maior agilidade na flexibilização das operações produtivas dessas grandes organizações. Conforme Ritter, Wilkinson e Johnston (2004), o desafio dos gestores é desenvolver uma rede que possibilite a conexão dos recursos de sua organização com os recursos dos demais agentes da rede.

Quanto às PMEs, a satisfação para com a "Feira Reversa" advém do fato de que a mesma se revelou uma excelente opção para a identificação de oportunidades de negócio que viabilizem uma maior utilização de seus recursos produtivos, colaborando assim para a amortização de investimentos já realizados por essas organizações.

\section{Artigo recebido em 07/06/2006 Aprovado para publicação em 26/03/2008}

\section{REFERÊNCIAS}

AMATO NETO, J. Redes de cooperação produtiva e clusters regionais: oportunidades para as pequenas e médias empresas. São Paulo: Atlas, 2000.

AMBROS, J. A relação usuário-produtor em empresas da cadeia automobilística gaúcha. 2000. 257 f. Tese (Doutorado) - Universidade Federal do Rio Grande do Sul - UFRGS, Porto Alegre, 2000.

ANDERSON, J. Relationships in Business Markets: Exchange Episodes, Value Creation, and Their Empirical Assessment. Journal of the Academy of Marketing Science, v. 23, p. 346-350, 1995.

ARGYRIS, C.; PUTNAM, R.; SMITH, D. Action Science. San Francisco: Jossey-Bass, 1985.

BECKHARD, R.; HARRIS, R. Organizational Transitions: Managing Complex Change. 2. ed. Reading: Addison-Wesley, 1987.

BENGTSSON, M.; KOCK, S. Coopetition in Business Networks to Cooperate and Compete Simultaneously. Industrial Marketing Management, v. 29, n. 5, p. 411-426, 2000.

CASAROTTO FILHO, N.; PIRES, L. H. Redes de pequenas e médias empresas e desenvolvimento local: estratégias para a conquista da competitividade global com base na experiência italiana. São Paulo: Atlas, 1999.
CHECKLAND, P.; HOLWELL, S. Action research: its nature and validity. Systems Practice and Action Research, v. 11, n. 1, p. 9-21, 1998.

COGHLAN, D.; BRANNICK, T. Doing Action Research in Your Own Organization. London: Sage, 2001.

COLLINS, R.; BECHLER, K.; PIRES, S Outsourcing in the Automotive Industry: from JIT to Modular Consortia. European Management Journal, v. 15, n. 5, p. 498-508, 1997.

COUGHLAN, P.; COGHLAN, D. Action research for operations management. International Journal of Operations and Production Management, v. 22, n. 2, p. 220-240, 2002.

COUSINS, P.; CRONE, M. Strategic models for the development of obligation based inter-firm relationships. Journal of Operations and Production Management, v. 23, n. 12, p. 1447-74, 2003

COX, A. The art of the possible relationship management in power regimes and supply chains. Supply Chain Management: An International Journal, v. 9, n. 5, p. 346-356, 2004.

DOZ, Y.; HAMEL, G. Alliance advantage: The art of creating value through partnering. Boston: Harvard Business School, 1998.
EASTON, G. Industrial networks: a review. In: AXELSSON, B.; EASTON, G. (Org.). Industrial Networks: A New View of Reality. London: Routledge, 1992.

EDEN, C.; HUXHAM, C. Action research for management research. British Journal of Management, v. 7, p. 75-86, 1996.

GIANNOCCARO, I.; PONTRANDOLFO, P. The Organizational Perspective in Supply Chain Management: An Empirical Analysis in Southern Italy. The International Journal of Logistics: Research and Applications, v. 6, n. 3, p. 107-123, 2003.

GREENWOOD, D.; LEVIN, M. Introduction to Action Research. Thousand Oaks: Sage, 1998.

GUMMESSON, E. Qualitative Methods in Management Research. 2. ed. Thousand Oaks: Sage, 2000.

HUMPHREY, J.; LECLER, Y.; SALERNO, M. S. Global strategies and local realities: the auto industry in emerging markets. London: Macmillan, 2000.

JARILLO, J. On Strategic Networks. Strategic Management Journal, v. 9, p. 31-41, 1988.

JOHNSTON, D. et al. Effects of supplier trust on performance of cooperative supplier relationships. Journal of Operations Management, v. 22, n. 1, p. 23-38, 2004. 
KAMP, B. Formation and evolution of buyer supplier relationships: Conceiving dynamism in actor composition of business networks. Industrial Marketing Management, v. 34, n. 7, p. 658-668, 2005.

KRAUSE, D. R. Supplier development: current practices and outcomes. International Journal of Purchasing and Materials Management, v. 33, n. 2, p. 12-19, 1997.

KRAUSE, D. R.; SCANNELL, T. V.; CALANTONE, R. J. A Structural Analysis of the Effectiveness of Buying Firms' Strategies to Improve Supplier Performance. Decision Sciences, v. 31, n. 1, p. 33-55, Winter 2000.

KRAUSE, D. R. et al. Supplier Development Practices: Product-and Service-Based Industry Comparisons. Journal of Supply Chain Management, v. 38, n. 2, p. 13-21, Spring 2002.

LINK, P.; MARXT, C. Integration of risk and chance management in the cooperation process. International Journal of Production Economics, v. 90, n. 1, p. 71-78, 2004.

LOESER, B. How to Set Up a Cooperation Network in the Production Industry: Example of the Huber + Suhner AG. Industrial Marketing Management, v. 28, n. 5, p. 453-465, 1999.

McNIFF, J.; LOMAX, P.; WHITEHEAD, J. You and Your Action Research Project. London: Routledge, 1996.
MUDAMBI, R.; HELPER, S. The close but adversarial model of supplier relations in the U.S. auto industry. Strategic Management Journal, v. 19, p. 775-792, 1998.

RICH, N.; HINES, P. Supply chain management and time based competition: the role of the supplier association, International Journal of Physical Distribution and Logistics Management, v. 27, n. 4, p. 210-225, 1997.

RING, P.; VAN DE VEN, A. Developmental Processes of Cooperative Interorganizational Relationships. Academy of Management Review, v. 1, p. 90-118, 1994.

RITTER, T.; WILKINSON, I.; JOHNSTON, W. Managing in complex business networks. Industrial Marketing Management, v. 33, n. 3, p. 175-183, 2004

SANTOS, L. A. V. Comitês técnicos. Revista Painel Automotivo, Porto Alegre, n. 37, p. 4-5, 2004.

SCHEIN, E. Process Consultation Revisited: Building the Helping Relationship. Reading: Addison-Wesley, 1999.

SMOCK, D. Supply Chain Perspective: Get Set to Board the Productivity Express. Supply Chain Management Review, p. 113-117, May-June, 2001.

SPEKMAN, R.; CARRAWAY, R. Making the transition to collaborative buyer-seller relationships: An emerging framework. Industrial Marketing Management, v. 35, n. 1, p. 10-19, 2006.
SUSMAN, G.; EVERED, R. An assessment of the scientific merits of action research. Administrative Science Quarterly, v. 23, p. 582-603, 1978.

SYDOW, J. Inter-Organizational Relations. In: Warner, M. (org.). International Encyclopedia of Business and Management, London: Routledge, 1996.

TAN, K.; WISNER, J. A study of operations management constructs and their relationships, International Journal of Operations \& Production Management, v. 23, n. 11, p. 1300-1325, 2003.

TICHY, N. Networks in Organizations. In NYSTROM, P.; STARBUCK, W. (Org.): Handbook of Organizational Design. Oxford: Oxford University Press, p. 225-249, 1981.

TUTEN, T.; URBAN, D. An Expanded Mode of B2B Partnership Formation and Success. Industrial Marketing Management, v. 30, n. 2, p. 149-164, 2001.

ZILBOVICIUS, M.; MARX, R.; SALERNO, M. S. A comprehensive study of the transformation of the Brazilian automotive industry: preliminary findings. International Journal of Automotive Technology and Management, v. 1, n. 3, p. 10-23, 2002.

WHYTE, W. Participatory Action Research. Thousand Oaks: Sage, 1991

\title{
SOBRE OS AUTORES
}

\section{Giancarlo Medeiros Pereira}

Universidade do Vale do Rio dos Sinos - UNISINOS

End.: Av. UNISINOS, 950 - Bloco 5A - São Leopoldo - RS - CEP 93022-00

E-mail: gian@unisinos.br

\section{Miriam Borchardt}

Universidade do Vale do Rio dos Sinos - UNISINOS

End.: Av. UNISINOS, 950 - Bloco 5A - São Leopoldo - RS - CEP 93022-00

E-mail: miriamb@unisinos.br

\author{
Albert Geiger \\ Instituto Gaúcho de Estudos Automotivos - IGEA \\ End.: Av. Assis Brasil - Porto Alegre - RS \\ E-mail: ageiger@terra.com.br
}

